\begin{tabular}{ll}
\hline \hline MINING AND METALLURGY INSTITUTE BOR & ISSN: 2334-8836 (Štampano izdanje) \\
UDK: 622 & ISSN: 2406-1395 (Online) \\
\hline \hline
\end{tabular}

Snežana Todosijević ${ }^{*}$, Miloš Todosijević ${ }^{* *}, Z$ Zoran Katanić ${ }^{* * *}$, Damnjan Radosavljević ${ }^{* * * * *}$

\title{
CHANGES IN A FUNCTION OF TRANSFORMATION AS THE CHALLENGES OF TOMORROW
}

\begin{abstract}
In the world of growing uncertainty, a change is the road without real purpose. Upcoming events can be successfully planned and controlled in a shorter time perspective. With time distance from the current standing point, the level of uncertainty increases while probability of outcomes of events that occurred with an effect of change decrease. Dominant challengers of changes in the enterprises are the technical progress and competition. Reaction of an enterprise is its answer on challenges of changes. At the beginning, we think that we know where the change will take us, and expressed if it will be a fact for us to last as long as possible, because of the fact that at some point end will come to the existing, because a change with some other working change is inevitable. Ability to understand changes is a condition to its implementation. Changes in terms of development require an adaptation and active recurrent action, and who manages to adapt to the developing trends and conditions of environment will last and exist, who does not, will disappear.
\end{abstract}

Keywords: changes, artificial intelligence, digitalization, evolution, transformation

\section{INTRODUCTION}

The twentieth century gave us radio, television, internet, rockets, atomic reactors, nuclear energy, and brought us to an era of electronic computers, we witnessed occurrence of applied mathematics, operative research and cybernetics. Research in the field of theory of prediction, whose pioneers were Norbert Viner and Julian Bayglo, have determined approach to this matter. We witnessed computer, sensor, chip...

Bioengineering, artificial intelligence, information technologies come with the characteristics of universal diffusion whose paradigm is made by the computer, telecommunication and robotics. Evolutionary approach in economy becomes overall accepted and with all new things comes digital Darwinism.

Even though it deals with the "unfriendly environment", an enterprise's duty is to conducts changes up to date, better than anyone else from competition. Condition for development and survival is found in abilities, knowledge and skills

\footnotetext{
* Ph. D, University of Pristina, Faculty of Economics Kosovska Mitrovica

** MSc, Cdsportsgroup

**** Ph. D. Assistant professor, College of Professional Medical Studies "Medika”, Belgrade

${ }^{* * * * *}$ Full professor, University "Union Nikola Tesla, Mladenovac, Belgrade, damnjar@mts.rs
} 
that are better than the ones competition has. Expenditure is their symbol. ${ }^{1}$

Just like nomadic tribes, the modern companies conduct their healthy competition within their possibilities, and on the outside with non-stop movement from one market on to the other, where their abilities, old and new can be sustained. Organizations and its competitors, as well as their markets, are in constant movement [1]. Primary goal is in business result, which occurs as a measure of success in real time expressed through finance. Diversification of activities of compounding of process imposes a need for the structural-sectoral organization and action [12]. Evolutionary economy, backed up with digitalization and methodological process of rationing capital, created a sequence of complex and mutually conditioned changes. Networked economy and communication "everyone with everyone" happened. Digitalization has brought a price downfall in communication industry and created a new approach in rationing capital and investment and developing activities. These transformation process have hit the strategies and pointed out a need that the managerial teams need to be formed interdisciplinary.

Basic collection of changes, which caused sets of transformations in all mutually connected sectors of functioning of one system, is in abandoning the "Taylorism" as the "art of mindfulness of giving orders" and affirmation of horizontal hierarchy whose the main characteristic is in ability of management to achieve the process of mobilization of right personnel for the benefit of job that has to be done [7].

Chances and possibilities for changes are found in the world of competition and technical progress. Innovative change and technological superiority are the key to everything, even business success. "Change is nowadays a constant measure" [12] and "nothing is as steady as a change[12].

Do the new technologies and technological progress endeavor to change the world? Not only the world, but before all conscience. Digital process and on them based and put in system AI, does not show any unjustified fear of upcoming digital times, because the digital times are in the essence evolutionary times, but are trying to take control of the system of functioning of what a man has created so that the creation does not become the opposite. This is because of the fact that the cyber world and deviation of mind never stand still.

\section{AI AND DEVELOPING TRANSFORMATIONS}

Changes of course in managing the complex dynamic systems, will take action under the influence of abilities to accept the innovative achievements on plan of digitalization, robotization and AI. Transformation process will be a function of ability to react to the changes.

Developed world, does not only try to take control over AI, but makes a good work in doing so. Digitalization with robotics and AI will "retire markets", just like a free market eliminated feudalism at one point.

Starting with the fact that in the next 20 years transformation process and influence on trade, services, production process (that are becoming more determined as well as flexible), education system, culture will be present... and way more dynamic than the ones in the past 20-30 years, like computers, semiconductors, internet etc. Need for crea-

\footnotetext{
${ }^{1}$ In the Republic of Srpska in a restaurant there was a slip of paper on the table with the following content: "It is forbidden to just sit in the restaurant"
} 
ting challenges is put at the first place of scene of creating and using the achieved results, no matter the sources. Economy of small countries through the transformation process, will achieve the process of adjustting in redistribution of economic power at the global level (Todosijevic R., Todosijevic Lazovic S. 2017).

Normative predictions show that the digital Darwinism and AI will in the next 20 years be biggest stimulant for the social and economic development. AI, robotization, and digitalization are seen as a critical mission by the skeptics at this point in time. But wasn't that the case with all the new things that happened through the creative world history. Resistance is always present, because many are striving toward equilibrium. However, history shows and proves that the greater the resistance toward changes is, the greater the destructing action of progress and change is. Transformation processes are the result of materialization of changes as the thoughtful experiments and research achievements.

AI creates objective conditions for overcoming the negative, stagnating or destructing actions of changes because it provides the realistic chances for affirmation the positive outcomes. Investments and time are suffering significant reduction and efficiency is growing. Digital process' and AI are not "fire escape" for evacuation, but are key aspect for developing models, process of decision making and management. Operationalization of systems is becoming superior in comparison to existing dysfunctional democracies. In the USA, a democratic presidential candidate stated that : "China is using technology in order to perfect dictatorship" [3]. But that is not a human answer to a human question. Scientific achievements are the first and foremost in a function of human harmony.
We are the witnesses of universal optimism about potential of digitalism and AI for advance of mankind. Unjustified fear is being spread from "machines with intelligence that could be more dominant than humans". Fear of future in imminent to the human behavior. However, it has always been finding elements for its protection from eventual possible claustrophobic situations and outcomes. Do AI and digitalization with robotization carry messages harmful for the existence of our world? Are we threatened with an unforeseen revolution of conscience and behavior or is evolution of truth reality normal? By confronting challenges of future in the center of attention is always wanted and projected - based on a trial of events intended future. Fear of nuclear war, fear of fire, flood, other natural disasters, fear of scientific achievements is only the humans ability to take control of occurrences and processes that are found in nature. Aren't we, today's people, result of AI of some unknown evolutionary ancestor, who we are in the absence of protection destroyed as a competition?!

Optimists agree that human greatness consists of freeing from destiny and that it will not confront with a possibility of its own destruction. They will always be able to project ways of self-defense. Pessimists would like to "lock or burn" progress. That is not possible, but a positive affirmation of the scientific achievements with elements of existing self-defense and control is always possible. Bio chip is maybe for now the far future. The new strategies are defined and formulated while the old "winning" ones are redefined. Systematic and partial research are being more and more rapid, a question is if we will experience any new revolutionary boom in the near future or if the digital Darwinism, by evolutionary laws determine direction and pace of the total social deve- 


\section{STRATEGIC TRANSFORMATIONS}

lopment. Cybernetic doily, that exists, and that was discovered by the human and constantly improved by the human, will intend to, without destructive conscience, constantly sustain state of a long-term existing equilibrium. More radical deviations from the natural evolution, even in that world, in which situation we are today, is just not possible or to be more precise, will not happen. Robots, as the networked functioning machines are fed with information, digital process and AI are occurring as the stars in a far horizon, that do not have enough light to illuminate space on which they are focused, but they do not lose hope from a position of creation to become suns one day. Sun is as we know source of life. We are experiencing a new reveal of nature and evolution that is going its own path and it is not important for it what is it that we know about and its way of structuring and functioning, but important thing is to enlarge our knowledge powers compared to it. That will be the biggest step to self-defense of eventual negative influences. In fact, we are in a position of occurring the golden age of AI in which synthesis of many knowledge from the past characters is achieved and it has built in the scientific prediction.

Technologies that will as a base have $\mathrm{AI}$, will be carriers of the future technological era and produce the real goods as well as the facts for future. Standardization and integration of the system will bring to downfall of communication expenses and affirmation the space independent from location, which will result in a higher flexibility, as in designing, building or implementation the technical systems and big contribution to that will have development of an intellectual capital. The main function of an enterprise is a result, and that will affect an integration of dominant technologies in the financial flows and $5 \mathrm{G}$ network.
The first step in "strategy" is defining a concept of a job and strategy of participation [1]. Personal reaction of Chinese president $\mathrm{Xi}$ Jinping in regards to loss of the worlds champion of the game "Go", with statement that the word is about technology in which China will have to be the leader, have set the precise goals for 2020 and 2025, which have paved the China's way to dominance of their creation of AI technologies and their use until 2030 [3]. Leading role is on private companies that have achieved a concentration of personnel, capacity and means. China's achieved result is 2.5 times patents in the fields of AI and IT than in the USA. In 2020 in China there will be 3 times more computer science graduates than in the USA. Leas are evident.

The AI and technologies integrated with it, are developed and achieved by the private companies, universities and problem oriented institutes, independent and as the fractions of universities. We can see that military establishments of the world super powers are tapping in place in regards with the dynamics of this field. Indicators of prosperity can be found in the following fields:

- development and innovation of products with market orientation;

- development and testing of products for financial markets;

- patents, licenses and scientific research magazines;

- results of population in international competitions;

- talents of national operative environment.

On Stanford, based on a theory of recognition, they have developed algorithms for AI, where with the unbelievable preciseness are discovered deviations with scanning just one photography. While San 
Francisco have just recently forbidden face recognition technology, Chinese have given an access to four leading companies for the new technologies to their data base with photos of more than 1.4 billion citizens. Estimate is that the Chinese companies that are developing the new face recognition technologies, possess million times more photos than their American competitors. Imagine what different kind of selection based on AI and algorithms with Stanford can be done by people who possess these information and technology.

AI has developed rapidly in the field of languages and linguistics. Dead languages will come to life. Plans for air traffic and unmanned aircraft, things are already going on based on the predefined software on one side and production of hardware that will react on that software on the other side. The main procurer of the US army with drones until 2017 were the Chinese companies. Company "DJI" controls more than $70 \%$ of world market with the unmanned aircraft and drones. These aircrafts and drones would in technical sense represent the small hobby toys, if they did not have the element of AI which gives them a computer sight based on which they recognize the weapons, drugs, criminals, radars etc. Smart house, smart city, smart car, smart glasses... $5 \mathrm{G}$ infrastructure occurs.

In the field of ecology, the sensor technologies are developed that precisely sort out a dump based on its source characteristics, based on AI and theory of recognition: glass, wood, plastic, paper and even organic waste.

Financial markets are not still, they are aware of reality. From every $\$ 10$ invested in the field of AI in 2018, \$5 have gone to Chinese and $\$ 4$ to US companies. From ten largest AI startups, a half are American and half are Chinese.

Chinese investments in research and development of technologies that are based on
$\mathrm{AI}$, have come to the point of American investments, and that reflects on results as well. It is probably about the strive to implement the intellectual base for generation advantage on a plan of recognition and AI. Based on the reliable sources about trends of development of AI, China will in 2020 surpass USA on first place in the number of cite in $50 \%$ of drawings in the field of AI.

High intensity is in the plan of developing hardware. Even ten years ago, prognostics had it that after $202080 \%$ of people will work in the tertiary sector and IT, and barely $20 \%$ in the primary and secondary duties. Change is happening in levels and quantum of labor as well as creation of values from classic jobs toward non material activities. The secondary and tertiary sectors, that are based mostly in IT, with characteristics of invisibility and automation in occurrence and characteristics of speed, are taking over basic function in development of economy of the developed world and is shifting traditional ways by conquering them [9].

It is shown that, like industry, traffic, trade, agriculture and other activities have with their development encouraged development of secondary and tertiary activities, now we have opposite transformation process that digitalism, Darwinistic-evolutionary approach and IT are more and more being industrialized towards the cited activities, including public sector, finance and culture.

\section{STATE OF THE SPIRIT AND TRANSFORMATION PROCESS}

Enterprises today are adjusting to user by the "code halos" which is their ability to mapping behavior. They are the users and life cycle of an enterprise, life cycle of product and life cycle of period of dominant technology. State of spirit of an enterprise 
determines ability of technical and technologically innovative development. Research has shown that the enterprises, that have accepted digital transformations and existence of digital Darwinism, are far ahead of their competition and have entered much earlier in wanted future. Enterprises that have encouraged process of digital Darwinism, have managed to achieve growth of value especially in sector of secondary economy.

Some authors have stand point that changes are taking place exponentially, but that is a characteristic of scientific development, so that cannot go too far, because in real world there are now conditions for existence of such system that could achieve extreme results, because the system like that would fall apart. Evolution either does not have same pace of changes, because every time when it comes to epochal discoveries, like in case of electricity, time is necessary for creating the conditions for implementation and spread of use of such discovery. However, the process becomes faster, and radically looking time between the discoveries and their materialization is becoming shorter. For photography it took 112 years, for radio 56 and for mazer only a week.

For use the digital Darwinism in the social economic systems, a variability is important, as well as the selection and gradual changes. We are the witnesses of change from evolutionary change of economic knowledge to economy of many sizes, definitions and constant changes [13]. Evolutionary performance is anatural continuum of former relations in the world of labor and introduction to the digital Darwinism.

For certain fields of techniques such as "Bionics", it has only become natural, for problem solutions in nature to be used as models for technical problem solutions. On that basis, in the meantime, an interesting structural model for organization of an enterprise has been developed. Howard
Bloom has written a book "The Evolution of Mass Mind from the Big Bang to the 21st Century" in which he speaks about sustaining life from bacteria to internet thanks to the grouping selections and group mind which is now seen as the "global brain". This is brilliant evolutionary idea that mankind needs in order to understand that above an individual mind there is a multiplied mind of people as a mind of mankind. The word is about strong provocative idea. It is about historical "tour de force", on evolutionary basis with accent on complexion and modernity to achieve a functional bond of elements of the system in an organizational structure.

In text "Artificial Intelligence", Garry McGovern says: "Cyber space is new space; earth and space are old space; space without matter is vacuum and nothing exists in vacuum but vacuum. What is matter of cyber space? It is digital. Atoms of that space are digital bits - digital "mater" that is non material. Did we reach and when will we reach cyber space and will we bring there our old matter?! These questions alone and much of unknown have served as motive for this work, because it is shown necessary to impose following facts which are mostly results of social and cultural evolutionary theory. Rules do not have to be brought by someone with conscious intention, they come with evolution of interaction of individuals and interaction with their surrounding through a process that is analogue to mutation and selection [12]. Rules are most of the time unknown to people who do not recognize them but act tactically. Rules of behavior in this manner are not free norms, but they represent the most important part of adaptation of man to one surrounding about which details he can never know enough in order to direct his behavior in accordance with the consequential bonds and in that way rationally act. 
Rules of the game and behavior are not fixed but are subjected to evolutionary changes, meaning that new challenges for transformation can bring to new rules, and second, that groups that had non purposeful rules of behavior did not have ability for survival. Social and cultural evolution does not rely on the individuals and its congenital characteristics, but rely on the institutions, cultural background and acquired skills. Rules that actually act, and that have in relatively late phases of social and cultural evolution been modified consciously by the set rules, are one of the most important parts of mechanism of real control and regulation of one system.

In process, which reminds the observers on management of Amazon and Google, the Chinese president $\mathrm{Xi}$ Jinping has defined the key indicators of performance for development on AI technologies. State has given large amount of financial means for many specialized programs and projects, and concentrated research personnel has been provided as well, which made it possible to achieve the maximum realization of strategy as a whole as well as the partial strategies [2].

We point out that in the process of development every state and its government has responsibility, with interests in freedom and dignity, strive toward following: to provide, based on the net investments, productive hiring of unemployed labor force and to work on protection of their own producers. China has a way to protect companies (on domestic market), support national champions (through subsidies and availability to government information resources) and make it possible for leading corporations in the field of AI to have the main word.

In the "German Ideology", the creators of historic materialism remind us: "On the beginning of history it should recreate every invention every day in every place in a different way". [5]
Performance questions represent a stimulation for development of companies and their constitute parts. The "Sharp eyes" will monitor and control public and private property as well as the infrastructure for unmanned cars. Accent is on the "smart cities". Competition does not stand still and achievements of technological progress are moving rapidly. Speed is on the scene. Amount and quality of information are the main factors of advancement and implementation of AI.

\section{STRATEGIC TRANSFORMATION}

The starting point for strategic transformation is a definition of work on the fields in which the enterprises want to act. From the general strategy comes specter of partial following and operating strategies. Strategies of occurrence are based on: products/market and take into consideration functional and geo-spacing plans.

In practice, we undertake already the existing transformation process, assuming affirmation of wanted strategy with participation, that is based on companies strivings and understanding competition, technology and market.

It is shown that high value in secondary economy is a result of base of knowledge, and implementation of those knowledge into technology, process, production and people. Andrew Keen, Berkley in ook "Cult of amateur" defines reasons for fear of upcoming future. [3]

However, it is not human answer to human question, because human greatness is found in his ability to get free of destiny. Human will not confront with possibility of self-destruction by projecting robocop with software against himself, but will define his own defensive mechanism of survival.

In world of statistics "command and control" have important role in functioning of organization systems. Dynamic systems 
and their structure, under the influence of technical changes, must faster transform through managing function and system of decision making. Companies, striving toward digitalization and $\mathrm{AI}$, must react fast. New paradigm of management comes on scene.

The main strategy must be redefined in a function of company goals. Accent is on fortifying competition in ongoing period as a pawn for non-defined future. By facing great dynamic change in multiple aspects of competitive environment, way of functioning of organization paradigm, which types problems of management in stable timely and business conditions will not be sufficient any more. Fact changing on which paradigm relies is happening. [1]

Managing activities standpoint in an era of informatic economy are shifted in comparison to the industrialization era. For informatic era, it is not sufficient to the mass and fast implementation the new technology and manage it accordingly, is not enough. It has become more important to manage the untouchable values: ability to keep old and attracting new customers and market segments, implementing innovative services and products on targeted market, adaptation of characteristics of supply to the targeted user, mobilization of skills and knowledge of employees, and use of new IT [9].

Societies and their economies, which are on the doorstep of chaos, are facing loss of people and capital, must create strategies for strengthening institutionalism and institutions, if they do not want to enter a larger scale chaos which is absolute. In states in which capital is leaving no capital is coming. Question we need to ask could be: do we need influence of social, economic and political organizations in determining economic events? [8]

Parallel with discussions about policies and directions of growth and development, it has shown necessary a need to react as a way of microeconomic and macroeconomics paradigms. The new classic macroeconomy is more corresponding with the "new microeconomy". The new classic macroeconomy insists on reformulation of orthodox classic economy. The basic reformulation is concepted by rational expectations combined with concept of natural rate of unemployment which occurs as a result of efficient balance on the market. Starting point is supported by the stand point that every try for output or employment to stabilize over or under the natural rate of unemployment, by the use of fiscal or monetary policy, will show inefficient and will not change value of real variables to long or short term. Base for this view point is found in the fact that there is no compromise between inflation and unemployment, not even short term, respectively if both curves, short term aggregate supply and Philips' curve on short term are vertical. No matter if it is seen as development, monetarism is failing both as a strategy of growth and strategy of development. These aspects are leaving arguments of leading monetarists, which represent a standpoint that the economic policies of management of demand will result in shifts of output and unemployment from the natural rate of unemployment in a short term. Regarding that the new classic macroeconomy is emerging and trying to show futility of the Keyns' policy of managing demand and instead of that focus on economy of supply [6].

\section{CONCLUSION}

In order for digital transformation and AI to be successful, it is necessary to achieve the process of adaptation and active reverse action of an enterprise on its changing environment. Digital Darwinism represents an era in which the technology and society are 
developing faster than the companies can adjust. In the science of economic enterprise, there is a whole bunch of moves that show the evolutionary direction which is based on concepts and methods which have occurred in the movement of organizational development.

Modern development of an enterprise is seen through its ability to digitally transform on the trace of achieved level of working culture, technology implementation and social behavior on development itself. Enterprise with advanced digital technologies is becoming a living organism capable to evolve, and in that why it gains the characteristic of self-participating, adaptive and self-organizing system. The existence of an enterprise is achieved in the cybernetic doily. These doily theory of recognition and AI come to express whose action is more used in the decomposed systems. The current characteristic process in the world are: decomposition of systems on one side and globalization on the other. Decomposition is leading us to a growth of efficiency and certainty of managing decisions, while the globalization needs to strive to lower the risk that in fact shows that the managerial problems are decomposed to the units of subproblems and those decisions are made at the subproblem levels, and with that outcome is that we have brought a decision like it was brought on a whole level.

\section{REFERENCES}

[1] Davidsom M. (1995) The Transformation of Management, MacMillan Business, London, pgs. 196-197

[2] Grejem T. Elison (2019) Osuđeni na rat: Mogu li Amerika i Kina da izbegnu Tukididovu zamku? "profesor državne uprave na Harvardovoj Kenedi školi.
Bivši je direktor harvardskog Belfer centra $i$ autor knjige“"

https://www.standard.rs/2020/01/11/

kina-odmice-u-trci-za-vestackominteligencijom-1/u translationVladan Marković

[3] http://www.pcnen.com/portal/ 2010/11/07/

[4] https://www.standard.rs/2020/01/ 11/kina-odmice-u-trci-za-vestackominteligencijom-1/

[5] Marx K. Engels F. L'ideologie allemande. (I partie: Feuerbach), Ed. Sociales, Paris 1966. P. 90. (translation of the author)

[6] Pearce W. D., (2003) Modern Economics 4 ed, MacMillan, str. 308

[7] Todosijević R. (2010) Strategic Management, Volume 1, Faculty of Economics Subotica, p.158 (in Serbian)

[8] Todosijević R., Todosijević Lazović S., (2017) Institutionalism and Digital Darwinism, SM2017, International Scientific Conference on Strategic Management, Faculty of Economics, Subotica (in Serbian)

[9] Todosijević R., Todosijević Lazović S. (2016) Institutional Environment Behavior and Digital Darwinism, Andrić Grad, Proceedings: International Scientific Conference (in Serbian)

[10] Todosijević R., Todosijević Lazović S, (June 2017) Small State Economy Strategy in Redistribution of the World Economic Power, Vrućica, 2017 Scientific Conference on Corporate Governance; Association of Accountants and Auditors of the Republic of Srpska, Proceedings (in Serbian)

[11] Todosijević Lazović S., (2000) Cost Forecasting in the New Product Development Projects, Master Thesis, University of Novi Sad p.1 (in Serbian) 
[12] Todosijević Lazović S., (2010) The New Production Programs, Growth of Production Capacity and Economic Efficiency of Companies, Doctoral Dissertation, University of Novi Sad (in Serbian)
[13] Zelenović D., (2011) Intelligent Business, Basic Technology of a Serious Society, Prometej, Novi Sad, p.95 (in Serbian) 